\title{
Determination of a Proper Function Representing Cyclic Strength Deterioration in Non-ductile Reinforced Concrete Columns
}

\author{
Changseok LEE \\ Department of Architecture Engineering \\ Hanyang University \\ Seoul, Republic of Korea \\ e-mail: mtsonicc@g mail.com
}

\author{
Sangwhan HAN \\ Depart ment of Architecture Engineering \\ Hanyang University \\ Seoul, Republic of Korea \\ e-mail: swhan@hanyang.ac.kr
}

\author{
Hyeyoung $\mathrm{KOH}$ \\ Department of Architecture Engineering \\ Hanyang University \\ Seoul, Republic of Korea \\ e-mail: hyey.koh@g mail.com
}

\begin{abstract}
Cyclic strength deterioration occurs in structural components when subjected cyclic loadings. In analytical models, cyclic strength deterioration starts when accumulated damage exceeds a certain threshold. Generally, there two types of equations measuring accumulated damage: (1) displacement-based equation and energy-based equation. This study investigates three different combinations of damage accumulation equations for measuring cyclic strength deterioration of non-ductile reinforces concrete columns. The accuracy of equations is estimated using static and dynamic analysis.
\end{abstract}

Keywords-cyclic strength deterioration; damage accumulation equation; non-ductile reinforced concrete columns

\section{INTRODUCTION}

During cyclic load reversals, structural components experience cyclic strength deterioration. It is known as the most common types of strength deterioration, in which a structural component experiences a reduction in lateral strength [1]. So cyclic strength deterioration plays an important role in accurately predicting response of structural component, or entire system.

Former hysteretic models trigger cyclic strength deteriorations using two kinds of damage accumulation functions. Some hysteretic models incorporated cyclic strength deterioration as a function of imposed displacement history (displacement-based damage accumulation equation). Others incorporated cyclic strength deterioration as a function of hysteretic energy demand (energy-based damage accumulation equation) imposed on the model [1].

The rate of damage accumulation is controlled by several parameters required by the damage accumulation functions. These parameters may vary from element (or structural component) to element. For example, [2] incorporated cyclic strength deteriorations in excursion $i$ using energy-based damage accumulation equation:

$$
\beta_{i}=\left(\frac{E_{i}}{E_{t}-\sum E_{j}}\right)^{c}
$$

where $E_{i}$ is dissipated hysteretic energy, $\sum E_{j}$ is cumulated hysteretic energy, $E_{t}$ is hysteretic energy-dissipation capacity, $c$ is exponent defining the rate of cyclic deterioration. If $c$ is set as 1.0, the equation becomes linear, otherwise, nonlinear. $E_{t}$ and $c$ are such parameters that require proper calibration. These parameters may vary depending on the physical and geometric properties of structural components. For this reas on, parameters for damage accumulation equation should be carefully calibrated to match the test data, because incorrect calibration of cyclic strength deterioration can have a huge impact on structural response prediction [3].

Lignos and Kranwinkler [2] and Haselton and Deierlein [3] calibrated damage accumulation equation for ductile structural components (steel moment connections and reinforced concrete columns with flexure failure) using (1). Both researchers assumed $c$ as 1.0 for simplicity. This assumption resulted in almost constant strength reduction through out every excursion. This assumption may be valid for predicting cyclic strength deterioration of ductile structural components. However, the accuracy of simulating cyclic strength deterioration of non-ductile element is not validated. Moreover, considering displacement-based damage accumulation equation along with energy-based one could lead to more accurate prediction of cyclic strength deterioration of non-ductile structural components.

So in this study, energy-based and displacement-based damage accumulation is tested and validated for non-ductile structural components. For validation of damage accumulation equation, two reinforced concrete columns, each failed in shear and flexure-shear, is selected. 


\section{MODEL DEFINITIONS}

In order to determine proper functional form of damage accumulation equation for non-ductile reinforced concrete columns, this study used the Pinching4 material model proposed by [4] provided in the OpenSees software [5]. The Pinching4 model simulates a pinched load-deformation response with cyclic deteriorations in unloading and reloading stiffness and strength. The most outstanding feature of this model is that it considers both displacementbased and energy-based damage accumulation.

In Pinching4 model, the amount of cyclic strength deterioration in each excursion, $i$, is based on the damage accumulation equation proposed by [4]:

$$
\delta_{i}=\alpha_{1}\left(\frac{d_{i, m}}{d_{f}}\right)^{\alpha_{3}}+\alpha_{2}\left(\frac{E_{i}}{E_{c}}\right)^{\alpha_{4}}
$$

where $\delta_{i}$ (damage index) defines accumulated damage within hysteretic model on a scale of 0.0 (undamaged) to 1.0 (fully damaged or total collapse), $d_{i, m}$ is maximum imposed displacement, $d_{f}$ is failure displacement, $E_{i}$ is cumulated hysteretic energy, $E_{c}$ is energy demand capacity.

For determining the parameters in (2), a large computation is required due to excessive iterative calibration processes. To alleviate the computational difficu lty, the most efficient and accurate functional form of damage accumulation equation is selected among the three different damage inde x model:

1) Linear energy-based damage accumulation equation:

$$
\delta_{i, 1}=\alpha_{2}\left(\frac{E_{i}}{E_{c}}\right)
$$

2) Nonlinear energy-based damage accumulation equation:

$$
\delta_{2, i}=\alpha_{2}\left(\frac{E_{i}}{E_{c}}\right)^{\alpha_{4}}
$$

3) Combination of linear displacement-based and nonlinear energy-based damage accumulation equation:

$$
\delta_{3,1}=\alpha_{1}\left(\frac{d_{i, m}}{d_{f}}\right)+\alpha_{2}\left(\frac{E_{i}}{E_{c}}\right)^{\alpha_{4}}
$$

The required numbers of parameters to be determined for (3), (4) and (5) are one, two, and three, respectively.

The focus of this study is to investigate the impact of functional form of cyclic strength deterioration. Thus, other types of deteriorations that are available in Pinching 4 model, such as, unloading stiffness and reloading stiffness deteriorations are ignored for simplicity. Pinching parameters are visually calibrated to match experimental data.

\section{SELECTED REINFORCED CONCRETE COLUMN SPECIMENS FOR CALIBRATION}

To verify the accuracy of simulating reinforced concrete columns with various forms of damage accumulation equation, two column specimens experiencing shear and fle xure-shear failure are considered from column experiment performed by [6] Cyclic curves of each specimen is simulated using the Pinching4 model with three different damage accumulation equations stated above. The physical properties of selected reinforced concrete column specimen are listed in Table 1.

Where $b$ is column section width $(\mathrm{mm}), h$ is column section height $(\mathrm{mm}), s$ is transverse reinforcement spacing $(\mathrm{mm}), d_{c}$ is clear cover $(\mathrm{mm}), D_{l}$ is diameter of longitudinal reinforcement $(\mathrm{mm}), D_{t}$ is diameter of transverse reinforcement $(\mathrm{mm}), f_{c}{ }^{\prime}$ is compressive strength of concrete, $f_{y l}$ is yield strength of longitudinal reinforcement, $f_{y t}$ is yield strength of transverse reinforcement, $a / d$ is column span-to-depth ratio, $v$ is column axial load ratio, $\rho_{l}$ is longitudinal reinforcement ratio, $\rho_{t}$ is transverse reinforcement ratio.

TABLE I. PHYSICAL PROPERTIES OF SELECTED NON-DUCTLLE REINFORCED CONCRETE COLUMN SPECIMENS

\begin{tabular}{|c|c|c|}
\hline \multirow{2}{*}{$\begin{array}{c}\text { Physical } \\
\text { properties }\end{array}$} & \multicolumn{2}{|c|}{ Name } \\
\cline { 2 - 3 } & HPRC-10 & HPRC-19 \\
\hline$b(\mathrm{~mm})$ & 200 & 200 \\
\hline$h(\mathrm{~mm})$ & 200 & 200 \\
\hline$s(\mathrm{~mm})$ & 35 & 20 \\
\hline$d_{c}(\mathrm{~mm})$ & 12 & 12 \\
\hline$D_{l}(\mathrm{~mm})$ & 12.7 & 12.7 \\
\hline$D_{t}(\mathrm{~mm})$ & 5.5 & 5.5 \\
\hline$f_{c}^{\prime}(\mathrm{MPa})$ & 21.6 & 21.0 \\
\hline$f_{y l}(\mathrm{MPa})$ & 371 & 371 \\
\hline$f_{y t}(\mathrm{MPa})$ & 344 & 344 \\
\hline$a / d$ & 1.5 & 1.5 \\
\hline$v$ & 0.17 & 0.35 \\
\hline$\rho_{l}(\%)$ & 1.27 & 1.27 \\
\hline$\rho_{t}(\%)$ & 0.81 & 1.39 \\
\hline Failure mode & Shear failure & Flexure-shear failure \\
\hline & & \\
\hline & & \\
\hline
\end{tabular}



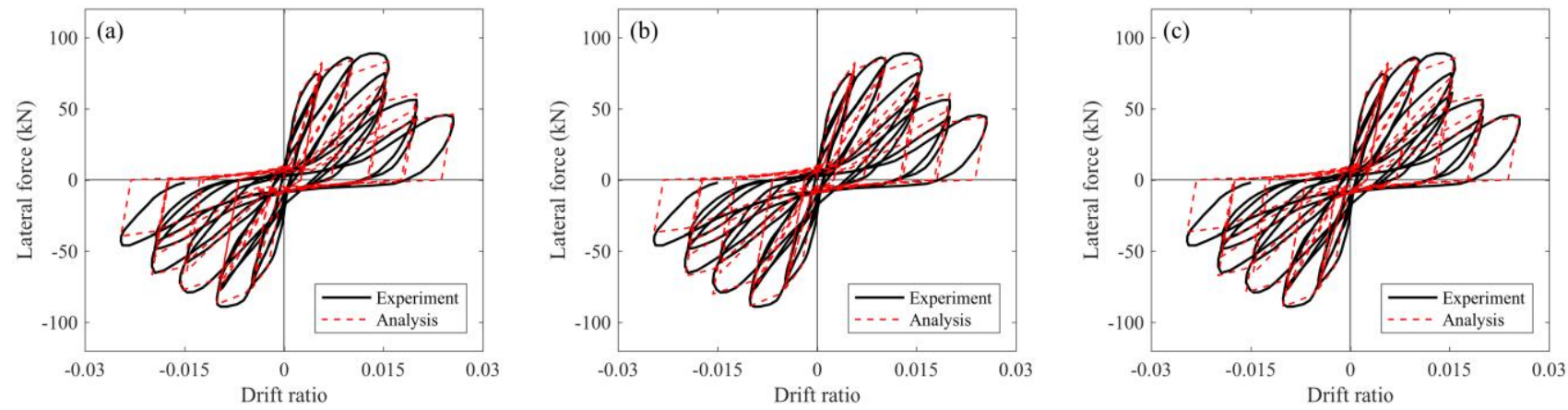

Figure 1. Comparison of specimen HPRC-10 and analytical result with respect to damage accumulation equation : (a) $\delta_{1}$, (b) $\delta_{2}$, (c) $\delta_{3}$
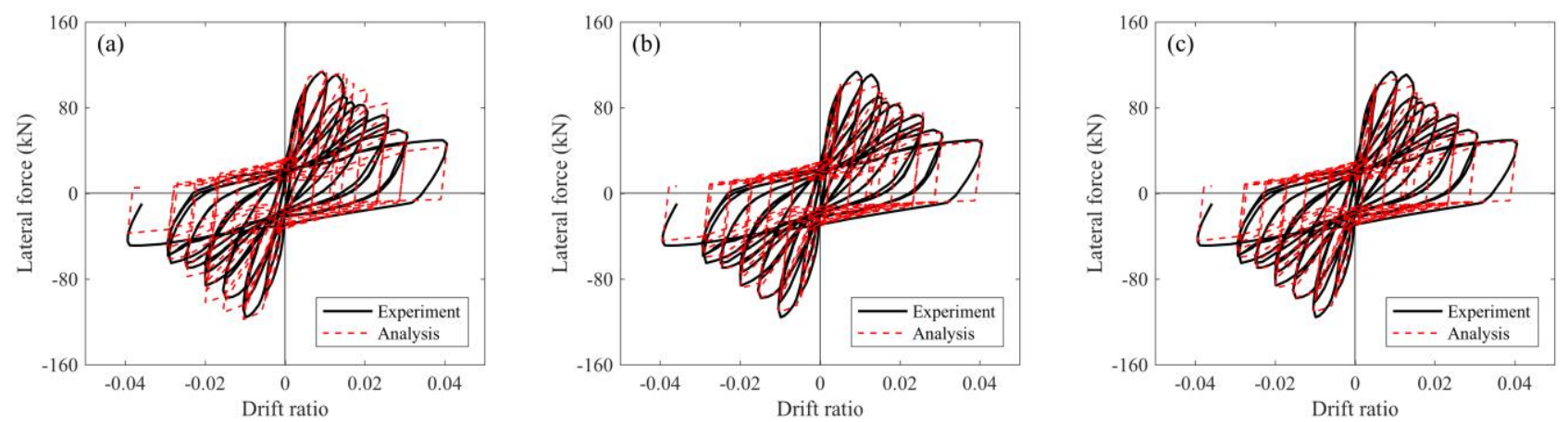

Figure 2. Comparison of specimen HPRC-19 and analytical result with respect to damage accumulation equation : (a) $\delta_{1}$, (b) $\delta_{2}$, (c) $\delta_{3}$

\section{COMPARISON OF ANALYTICAL RESULTS WITH RESPECT TO DAMAGE ACCUMULATION EQUATIONS}

\section{A. Static Analysis Results}

In this chapter, the accuracy of three different damage accumulation equations is compared through static analyses. Fig. 1 and Fig. 2 show actual and simulated cyclic curves of the selected reinforced concrete column specimens (HPRC10 and HPRC-19 respectively). By visually comparing overall results, simulated cyclic curves using three equations showed great accuracy.

The maximum lateral force of HPRC-10 [6] is $88.8 \mathrm{kN}$. The simulated maximum lateral force using $\delta_{1}, \delta_{2}$, and $\delta_{3}$ was $84.3,85.9,85.7 \mathrm{kN}$ respectively. Although $\delta_{1}$ showed the least accuracy, the error was only $5.34 \%$ to 3.38 and $3.62 \%$, compared with $\delta_{2}$ and $\delta_{3}$. However, the cumulative energy dissipation on the onset of failure showed similar errors (around 26\%). Each equation resulted similar amount of cumulative energy dissipation $(2.77 \mathrm{~kJ})$.

The maximum lateral force of HPRC-19 [6] is $113.4 \mathrm{kN}$ and simulated ones are $115.6 \mathrm{kN}, 107.3 \mathrm{kN}, 107.3 \mathrm{kN}$, respectively for $\delta_{1}, \delta_{2}$, and $\delta_{3}$. In this specimen, the error of $\delta_{1}$ was the smallest. However, just like the previous specimen, the errors of other equations showed very small amount of differences compared to the error of the best fitting equation. The error of predicting cumulative energy dissipation showed the opposite results. $\delta_{1}$ showed the least accuracy $(9.62 \mathrm{~kJ})$ co mpared to test result $(7.19 \mathrm{~kJ})$. Other two equations showed slightly better results than $\delta_{1}\left(9.21 \mathrm{~kJ}\right.$ for $\delta_{2}$ and $\delta_{3}$ ). The difference of errors between $\delta_{1}$ and others is less than $5 \%$.

It can be concluded that the predicted result of $\delta_{1}, \delta_{2}$, and $\delta_{3}$ showed negligible differences in simulating maximum lateral force and overall cyclic curves of given specimen. All three equations over-estimated cumu lative energy dis sipation for both column specimens. This was due to lack of considering stiffness deteriorations. For the simplest and efficient prediction, $\delta_{1}$ is the most appropriate.

\section{B. Dynamic Analysis Results}

In this chapter, dynamic response is compared. For comparing dynamic behaviors of damage accumulation equations, single degree of freedom (SDF) model is considered. Lumped mass is adjusted to match fundamental period of 1.0 second. SDF system is assumed to have viscous damping ratio of $5 \%$.

SDF system is then subjected to 22 pairs of far-field ground motion sets provided by [3]. The IDA approach, proposed by [7] is adopted for comparing dynamic response. In IDA, the intensity of each ground motion is scaled until inter-story drift increases without bounds.

Fig.3 compares median IDA curves of reinforced concrete column models calibrated to test data that has failed in shear and flexure-shear, respectively. y-axis is expressed as $\left(S_{a} / g\right) / \eta$ for ease of comparison [2]. $S_{a}$ is a measure of the ground motion and corresponds to the 5\% damped spectral acceleration at the first mode period of the SDF system, $g$ is gravitational acceleration, $\eta$ is the ratio of yield force and self-weight of SDF system. 


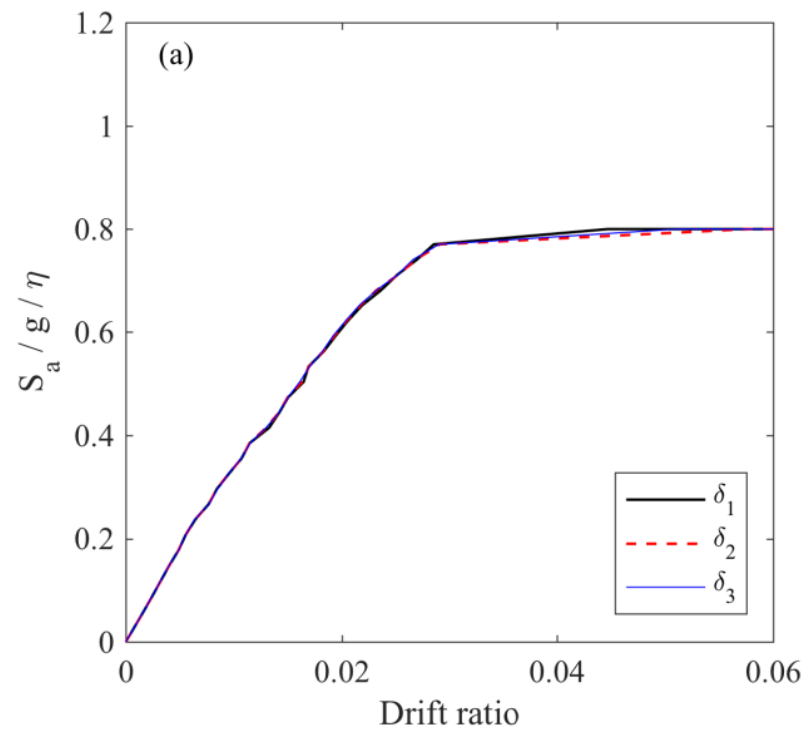

Figure 3. Median IDA curve of : (a) HPRC-10, (b) HPRC-19

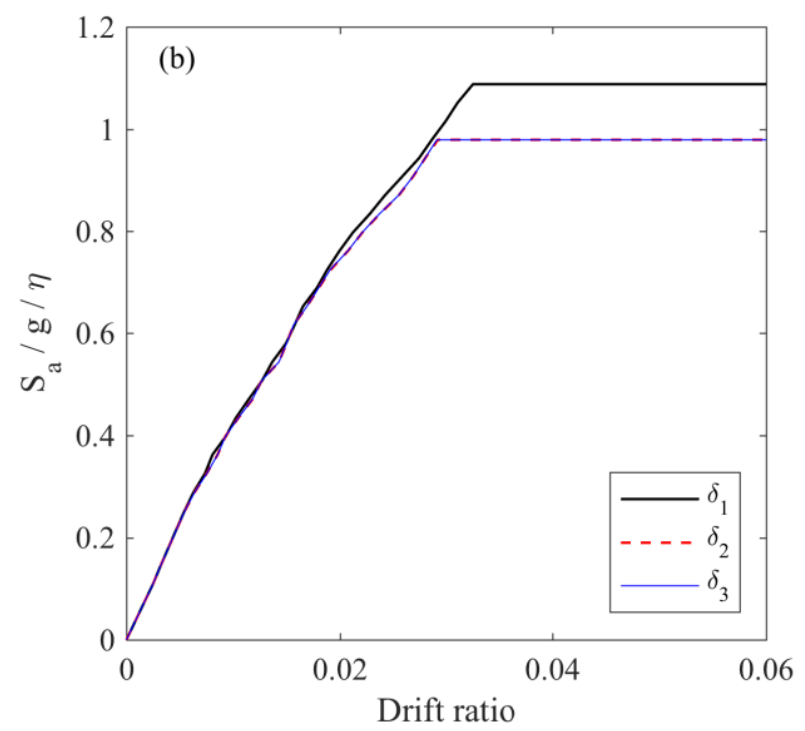

significantly improve the results of cyclic strength deterioration

\section{ACKNOWLEDGMENT}

The research was supported by the grant from the National Research Foundation of Korea (no. 2015R1A2A1A15055248).

\section{REFERENCES}

[1] FEMA P440A, Effects of strength and stiffness degradation on seismic response. Federal Emergency Management Agency, Washington, DC, 2009.

[2] L. F. Ibarra, R. A. Medina, and H. Krawinkler, "Hysteretic models that incorporate strength and stiffness deterioration", Earthquake Engineering \& Struct ural Dynamics, vol. 34, 2005, pp. 1489-1511.

[3] C. B. Haselton, and G. G. Deierlein, Assessing seismic collapse safety of modern reinforced concrete moment frame buildings, Pacific Earthquake Engineering Research Center, 2007.

[4] L. N. Lowes, N. Mitra, and A. Altoontash, A beam-column joint model for simulating the earthquake response of reinforced concrete frames. Pacific Earthquake Engineering Research Center, 2003.

[5] F. T. Mckenna, Object-oriented finite element programming: frameworks for analysis, algorithms and parallel computing. University of California, Berkeley, 1997.

[6] T. Nagasaka, "Effectiveness of steel fiber as web reinforcement in reinforced concrete columns", Transactions of the Japan Concrete Institute, vol. 4, 1982, 493-500.

[7] D. Vamvatsikos, and C. A. Cornell, "Incremental dynamic analysis", Earthquake Engineering \& Structural Dynamics, vol. 31, 2002, 491514. deterioration among the three different models. For aiming slightly better prediction, nonlinear energy-based model could be used. However, the combined model did not 